\title{
EFEITO DE DIFERENTES MÉTODOS DE SECAGEM EM Coffea canephora PRODUZIDO EM DIFERENTES ALTITUDES NO ESTADO DO ESPÍRITO SANTO
}

\author{
EFFECT OF DIFFERENT DRYING METHODS ON Coffea canephora \\ PRODUCED AT DIFERENT ALTITUDES IN THE ESPÍRITO SANTO STATE
}

${ }^{1}$ Andressa Coelho de Oliveira*

${ }^{2}$ Ana Mery de Oliveira

${ }^{3}$ Marcelo Giordani Minozzo

${ }^{4}$ Priscila Judacewski

\author{
${ }^{1}$ Instituto Federal do Espírito Santo. E-mail: andressacoliveira@outlook.com.br \\ ${ }^{2}$ Instituto Federal do Espírito Santo. E-mail: ana.mery@ifes.edu.br \\ ${ }^{3}$ Instituto Federal do Espírito Santo. E-mail: marcelocg@ifes.edu.br \\ ${ }^{4}$ Centro Estadual Profissional Olegário Macedo. E-mail: priscila_judacewski@hotmail.com \\ *Autor de correspondência
}

Artigo submetido em 27/01/2021, aceito em 04/03/2021 e publicado em 15/04/2021.

Resumo: O Brasil é referência no setor cafeeiro, com elevada contribuição do estado do Espírito Santo (ES), que se destaca como principal produtor de conilon (Coffea canephora) no país. Após o beneficiamento, o café é caracterizado de acordo com sua qualidade, que é influenciada por diversos fatores e interfere diretamente na possibilidade de agregação de valor ao produto. Grande parte dos fatores determinantes da qualidade está associada aos processos de colheita, processamento, secagem e armazenamento. Desse modo, objetivou-se com o presente trabalho avaliar a relação entre os principais métodos de secagem utilizados para o café conilon cultivado em diferentes altitudes e sua qualidade final. Foram utilizadas amostras de grãos secos em terreiro comum (TC), terreiro de cimento suspenso coberto com estufa (TS) e secador rotativo pelo método direto (S). A análise sensorial foi realizada através de degustação por julgadores especializados e a qualidade química foi avaliada por meio das análises de umidade, $\mathrm{pH}$, acidez total titulável e condutividade elétrica. As amostras apresentaram diferença significativa entre os diferentes métodos de secagem utilizados para todos os parâmetros avaliados. Não foi possível identificar um único método de secagem que promovesse amostras com parâmetros superiores de qualidade, indicando, portanto, que o uso de matéria prima de boa qualidade, aliado a manejo e processamento pós-colheita adequados, proporcionam produtos finais dentro dos padrões de qualidade, independentemente do método de secagem utilizado.

Palavras-chave: café; análise sensorial; conilon; pós-colheita.

Abstract: Brazil is a reference in the coffee sector, with a high contribution from the State of Espírito Santo (ES), which stands out as the main producer of conilon (Coffea canephora) in the country. After processing, coffee is characterized by its quality, which is influenced by several factors and directly interferes with the possibility of adding value to the product. Most of the determinants of quality are associated with the processes of harvesting, processing, drying and storage. Thus, the objective of the present work was to evaluate the relationship between the main drying processes used for conilon coffee at different altitudes and its final quality. We used samples of dry grains in a common terrace (TC), a suspended cement terrace covered with greenhouse (TS) and a rotary dryer by the direct 
method (S). The sensory analysis was carried out through tasting by specialized judges and the chemical quality was assessed through the analysis of humidity, $\mathrm{pH}$, titratable acidity and electric conductivity. The samples showed a significant difference between the different drying methods used for all evaluated parameters. It was not possible to identify a single drying method that promoted samples with superior quality parameters, indicating, therefore, that the use of good quality raw material, combined with adequate post-harvest handling and processing, provide final products within the quality standards, regardless of the drying method used.

Keywords: coffee; sensory analysis; conilon; postharvest.

\section{INTRODUÇÃO}

O café, cultura presente em mais de 80 países, destaca-se como uma commoditie significativa no setor agrícola (SEMEDO et al., 2018). O Brasil é referência no setor cafeeiro, sendo o maior produtor e exportador mundial de café (ICO, 2019) e o único país com produção em larga escala das duas principais espécies comercializadas do gênero Coffea, Coffea arabica e C. canephora (Conilon/Robusta) (RODRIGUES et al., 2015).

No Espírito Santo a cafeicultura exerce elevada importância econômica e social, "sendo responsável por 35\% do Produto Interno Bruto (PIB) agrícola capixaba, gerando aproximadamente 400 mil empregos diretos e indiretos" (INCAPER, 2018).

Devido às características genéticas apresentadas pelo Coffea canephora, como maior controle de transpiração e maior tolerância à seca (LAMBOT et al., 2008), genótipos do grupo Conilon são os mais cultivados no Brasil, sobretudo no estado do Espírito Santo (FERRÃO et al., 2017). O Espírito Santo é o maior produtor brasileiro de café Conilon, com uma produção aproximada de 10,5 milhões de sacas beneficiadas na safra 2019, representando um aumento de $11 \%$ em relação à safra anterior (CONAB, 2019).

Diversos trabalhos objetivando o estudo dos diferentes processos de secagem do café vêm sendo realizados, contudo, devido a sua maior comercialização, a maioria deles voltados ao Coffea arabica (AFONSO JÚNIOR et al., 2004; AFONSO JÚNIOR et al., 2006; BORÉM et al., 2008; LACERDA FILHO et al., 2006; SANTOS et al., 2009), que representa $65 \%$ da produção mundial de café (SANTOS, 2019).

\section{A qualidade do café Conilon é} ainda um assunto pouco explorado, entretanto, o conhecimento da influência dos tipos de secagem em sua qualidade, além de atender à expectativa do mercado consumidor, pode agregar significativamente no valor de comercialização do produto final.

Portanto, objetivou-se com o presente estudo avaliar a qualidade do café Conilon (Coffea canephora) quanto aos principais processos de secagem utilizados em diferentes altitudes de cultivo no sul do estado do Espírito Santo.

\section{REFERENCIAL TEÓRICO}

A qualidade do café relaciona-se diretamente à composição química dos grãos, sendo esta característica influenciada por fatores que vão desde a escolha do genótipo a ser utilizado, até as condições de processamento pós-colheita, incluindo secagem, armazenamento, torrefação e moagem (FRANCA et al., 2005).

A secagem é tida como a etapa de maior importância no processamento pós- 
colheita do café, diminuindo perdas diversas e sendo, portanto, essencial na preservação das características fisiológicas durante o armazenamento (GARCIA et al., 2004). No Brasil, os cafeicultores utilizam, basicamente, dois métodos para secagem: a secagem em terreiros ou a secagem em secadores mecânicos (FERRÃO et al., 2017).

A secagem em terreiro, apesar de trabalhosa e totalmente dependente de condições climáticas favoráveis, é muito comum, sobretudo em pequenas propriedades, sejam terreiros convencionais ou terreiros suspensos com estufa, que possibilitam um menor tempo de secagem e diminuição de processos fermentativos em relação aos primeiros (PIMENTA, 2003). Entretanto, com a elevação do volume de produção, a secagem artificial, realizada por meio de um sistema de ventilação forçada, tem ganhado destaque no setor cafeeiro, possibilitando, além da antecipação da colheita, menores perdas qualitativas e quantitativas (SILVA e LACERDA FILHO, 1984).

Pereira et al. (2020) enfatizam que a execução adequada dos procedimentos pós-colheita, destacando a colheita de frutos maduros e a secagem, são essenciais para a obtenção de uma bebida de qualidade. O método de secagem, quando inadequado, pode provocar alterações físicas, químicas e sensoriais indesejáveis, interferindo negativamente na qualidade de bebida do café (BORÉM et al., 2008).

A qualidade de bebida do café, característica de maior peso em sua comercialização, é obtida por meio da análise sensorial e é influenciada por diversos fatores (PIMENTA et al., 2008). Dentre esses fatores, pode-se citar o índice de acidez, cujo grau varia conforme local de origem, estádio de maturação dos frutos, colheita, tipo de processamento e secagem (SIQUEIRA e ABREU, 2006).
Destacam-se também os índices de condutividade elétrica, que, juntamente com a lixiviação de potássio, em estudo realizado por Prete (1992), apresentaram relação inversa com a qualidade de bebida.

Além desses, o pH apresenta-se como indicador de eventuais alterações nos frutos de café, como processos indesejáveis de fermentação pré e póscolheita. Segundo Siqueira \& Abreu (2006), características sensoriais mais aceitáveis ao consumidor são obtidas quando o $\mathrm{pH}$ se encontra na faixa entre 4,95 e 5,20, proporcionando uma bebida sem excesso de amargor ou acidez.

Abrahão et al. (2010) ressaltam a necessidade de os cafeicultores estarem atentos às diferentes etapas da produção, de maneira a atender às expectativas do mercado consumidor, e, por esse motivo, grande atenção deve ser dada ao processo de secagem quando se visa a obtenção de qualidade de bebida.

\section{MATERIAIS E MÉTODOS}

Foram obtidas amostras de café Conilon provenientes da última safra (2019/2020), submetidos a três diferentes processos de secagem, sendo eles: terreiro comum (TC) e terreiro de cimento suspenso (TS), ambos com revolvimento manual, e secador rotativo com fogo direto (S). As amostras TC e S foram fornecidas por produtores do município de Cachoeiro de Itapemirim - ES, localidade Tijuca $\left(20^{\circ}\right.$ $54^{\prime}$ S, $41^{\circ} 07^{\prime} \mathrm{W}$ ). A altitude da região é de aproximadamente 140 metros, o clima, de acordo com classificação de Koppen, é Aw tropical com estação seca, temperatura média anual de $23^{\circ} \mathrm{C}$ e precipitação 1293 $\mathrm{mm} /$ ano, aproximadamente.

A amostra TS foi obtida na localidade de Água Limpa, município de Alegre - ES ( $\left.20^{\circ} 47^{\prime} \mathrm{S}, 41^{\circ} 31^{\prime} \mathrm{W}\right)$, com altitude aproximada de 500 metros. O clima da região, de acordo com 
classificação de Koppen, é Cwa subtropical úmido, temperatura média anual de $22^{\circ} \mathrm{C}$ e precipitação 1200 $\mathrm{mm} / \mathrm{ano}$, aproximadamente.

Os frutos foram colhidos manualmente quando, aproximadamente, $80 \%$ dos frutos totais da planta estavam maduros, sendo acondicionados em sacos de estopa e posteriormente levados aos devidos processos de secagem.

Após secagem, foram retirados 3 quilos de cada saca contendo os cafés secos pelos diferentes métodos, sendo homogeneizados e conduzidos às análises descritas a seguir.

As análises foram realizadas em triplicata e, quando necessário, as amostras de café foram moídas em moinho de facas da marca Marconi (MA-340).

\subsection{DETERMINAÇÃO DA UMIDADE}

A determinação da umidade das amostras de café Conilon foi realizada de acordo com o método da estufa a $105^{\circ} \mathrm{C}$, por 24 horas, até obtenção de massa constante (BRASIL, 1992).

\subsection{DETERMINAÇÃO DO pH}

Para determinação do $\mathrm{pH}$ das amostras, utilizou-se o extrato obtido a partir de $2 \mathrm{~g}$ de amostra moída e diluída em $50 \mathrm{ml}$ de água destilada. A solução foi agitada em agitador mecânico por 1 hora a $150 \mathrm{rpm}$ e, em seguida, foi filtrada em papel de filtro. Da solução filtrada, retirouse uma amostra de $5 \mathrm{ml}$, que foi transferida para um béquer, onde realizou-se a leitura por meio de medidor de $\mathrm{pH}$ TECNOPON, modelo mPA 210, de acordo com metodologia descrita pela AOAC (1996).

\subsection{ACIDEZ TITULÁVEL}

Para determinação da acidez titulável, pesou-se $2 \mathrm{~g}$ de amostra de café moído, sendo diluídos em $50 \mathrm{ml}$ de água destilada e agitado em agitador mecânico por 1 hora a $150 \mathrm{rpm}$. A solução extrato foi filtrada e uma alíquota de $5 \mathrm{ml}$ foi separada e diluída em $50 \mathrm{ml}$ de água destilada. Como a coloração do café impossibilita a visualização do ponto de viragem, quando utilizada solução indicadora, a análise foi realizada com o auxílio de um medidor de pH. A medição foi realizada por meio de titulação com $\mathrm{NaOH}$ 0,1 N até pH 8,2, sob temperatura ambiente e os resultados foram expressos em $\mathrm{ml}$ de $\mathrm{NaOH}$ 0,1N 100 $\mathrm{g}^{-1}$ de amostra de café. $\mathrm{O}$ fator de correção da base utilizado foi de 0,85 (IAL, 2008).

\subsection{CONDUTIVIDADE ELÉTRICA}

Após secagem das amostras em estufa a $65^{\circ} \mathrm{C}$ pelo período de $48 \mathrm{~h}$, para uniformização da umidade, a condutividade elétrica dos grãos crus foi determinada adaptando-se a metodologia proposta por Prete (1992). Para cada amostra, foram utilizadas quatro repetições com 50 grãos crus sem defeitos visíveis, os quais foram pesados em balança de precisão de 0,0001 g. Em seguida, as amostras foram imersas em $75 \mathrm{ml}$ de água destilada e os recipientes foram colocados em estufa ventilada, em temperatura de $25^{\circ} \mathrm{C}$ por $5 \mathrm{~h}$, procedendo-se a leitura da condutividade elétrica da solução em condutivímetro modelo mCA 150 MS TECNOPON. Com os dados obtidos foram calculadas as condutividades elétricas, expressando-se o resultado em $\mu \mathrm{S} \mathrm{cm}^{-1} \mathrm{~g}_{-1}$ de amostra.

\subsection{ANÁLISE SENSORIAL}

As análises sensoriais foram realizadas no Laboratório de Análise e Pesquisa em Café - LAPC do Instituto Federal do Espírito Santo, campus Venda Nova do Imigrante, por seis julgadores credenciados Q-Grader (certificação mundial dada a profissionais de classificação e degustação de cafés), utilizando a metodologia de análise 
sensorial da Specialty Coffee Association of America, SCAA (2013).

Para cada tratamento, uma amostra de café Conilon foi torrada, obtendo ponto de torra referente entre os pontos \#65 e \#55 do disco Agtron, que corresponde a uma torra média. A torrefação foi executada com 24 horas de antecedência, respeitando-se, em seguida, o período de descanso da amostra de 8 horas em local fresco e escuro, conforme proposto por Pereira et al. (2019). Em seguida, realizouse a moagem da amostra e o preparo da infusão com água, em temperatura entre $92-95^{\circ} \mathrm{C}$, na proporção de 8,25 gramas de café moído para $150 \mathrm{ml}$ de água.

Cada amostra foi pontuada quanto ao aroma, sabor, acidez, doçura, sensação na boca, equilíbrio, conjunto, retrogosto, uniformidade, limpeza e defeitos, sendo atribuída uma nota global, considerando todas as características citadas.

\subsection{ANÁLISE ESTATÍSTICA}

Os dados foram apresentados como média \pm desvio padrão, sendo realizado teste de Levene para avaliar sua homogeneidade, considerando paramétrico o valor de $p>0,05$. Em seguida, a matriz de dados obtida das análises foi avaliada com Análise de Variância (ANOVA) complementada com o teste de comparação de médias de Fischer LSD. As análises estatísticas foram realizadas utilizando o software Statistica 7.0 (StatSoft Inc., Tulsa, EUA).

\section{RESULTADOS E DISCUSSÃO}

Os valores de umidade das amostras de café submetidas aos diferentes processos de secagem variaram de 9,13 a 11,88\% (Tabela 1), não excedendo o limite máximo de tolerância para café grão cru de $12,5 \%$ estabelecido pela Instrução Normativa $\mathrm{n}^{0}$ 8, de 11 de junho de 2003 (BRASIL, 2003). Ferrão et al. (2017) recomendam, para o armazenamento e comercialização do café Conilon, umidade dos grãos de $13 \%$ como sendo adequada. Segundo esses autores, a secagem excessiva acarreta em perda de peso e maior quebra de grãos no beneficiamento, já teores elevados de umidade favorecem o desenvolvimento de microrganismos no armazenamento.

Para os valores de $\mathrm{pH}$ do grão cru (Tabela 1), obteve-se uma variação de 5,20 a 5,76. Siqueira \& Abreu (2006) afirmam que os valores ideais para esse parâmetro devem estar entre 4,95 a 5,20. Já Balzer (2001) aponta como sendo ideal para o café Conilon grão cru a faixa de $\mathrm{pH}$ de 5,25 a 5,40. Dessa forma, somente as amostras provenientes da secagem em terreiro suspenso estariam dentro da faixa ideal. Os grãos secos em terreiro comum (TC) e secador (S) apresentaram valores superiores às faixas citadas, fato que pode acarretar na ocorrência de amargor ou acidez excessivos, em decorrência de transformações indesejadas nos frutos, que alteram o sabor.

Tabela 1: Médias e desvios-padrão de umidade e pH de café conilon seco em terreiro comum (TC), terreiro suspenso (TS) e secador rotativo (S) ${ }^{(1)}$

\begin{tabular}{ccc}
\hline & Umidade $(\%)$ & $\mathrm{pH}$ \\
\hline TC & $11.83 \pm 0.05^{\mathrm{a}}$ & $5.74 \pm 0.02^{\mathrm{a}}$ \\
$\mathrm{TS}$ & $9.17 \pm 0.04^{\mathrm{c}}$ & $5.21 \pm 0.02^{\mathrm{c}}$ \\
$\mathrm{S}$ & $10.55 \pm 0.03^{\mathrm{b}}$ & $5.60 \pm 0.03^{\mathrm{b}}$ \\
\hline (1) Médias com letras iguais, na vertical, não \\
diferem entre si pelo teste de Fisher, a 5\% de \\
probabilidade. Fonte: Os autores (2020).
\end{tabular}

Na Tabela 2 é possível observar os valores para determinação da acidez titulável total dos grãos, variando de 130,00 a $185,00 \mathrm{ml}$ de $\mathrm{NaOH} 0,1 \mathrm{~N}$ por $100 \mathrm{~g}$ de amostra. Não existem valores de referência para este parâmetro na legislação vigente, entretanto, valores mais elevados de acidez também estão associados à fermentação e/ou degradação 
(CARVALHO et al., 1994; BORÉM et al., 2008). Nota-se que o café proveniente da secagem em terreiro suspenso, diferente do esperado, apresentou os maiores valores de acidez total titulável, indicando a possibilidade de obtenção de um café de baixa qualidade por esse método, a depender de vários fatores, principalmente climáticos, durante o período de secagem.

Com relação à condutividade elétrica, amostras provenientes de secagem em terreiro comum apresentaram valores significativamente maiores em relação aos demais métodos, indicando uma maior degradação das membranas celulares nesse caso. Borém et al. (2008), avaliando a secagem do café em terreiros e em secador com ar aquecido a 40 e $60^{\circ} \mathrm{C}$, observaram aumento da condutividade elétrica à medida que ocorria elevação da temperatura de secagem, independentemente do tipo de processamento, fator que compromete a estrutura das membranas celulares, interferindo, dessa forma, na qualidade de bebida do café.

Tabela 2: Médias e desvios-padrão de acidez total titulável (ATT) e condutividade elétrica (CE) de café conilon seco em terreiro comum (TC), terreiro suspenso (TS) e secador rotativo (S) ${ }^{(1)}$

\begin{tabular}{ccc}
\hline & ATT $^{(2)}$ & CE $^{(3)}$ \\
\hline TC & $135.83 \pm 5.20^{\mathrm{c}}$ & $207.84 \pm 5.57^{\mathrm{a}}$ \\
TS & $182.50 \pm 2.50^{\mathrm{a}}$ & $111.99 \pm 4.73^{\mathrm{b}}$ \\
S & $164.17 \pm 1.44^{\mathrm{b}}$ & $69.68 \pm 3.82^{\mathrm{c}}$ \\
\hline
\end{tabular}

${ }^{(1)}$ Médias com letras iguais, na vertical, não diferem entre si pelo teste de Fisher, a 5\% de probabilidade. (2) ATT expressa em ml NaOH 0,1 N por 100 g. (3) CE expressa em $\mu \mathrm{S} \mathrm{cm}^{-1} \mathrm{~g}^{-1}$ de amostra.

Fonte: Os autores (2020).

Com relação à análise sensorial e os atributos analisados, as amostras obtiveram como nota global 40,42; 61,71 e 40,50 pontos (TC, TS e S, respectivamente). Analisando esses resultados, é possível inferir que a secagem em terreiro suspenso possibilita a obtenção de produtos com melhor qualidade. Este fato também pode ser explicado devido a amostra TS ser oriunda de maior altitude de cultivo, visto a relação positiva existente entre esta e a qualidade de bebida (MORELI et al., 2019; PEREIRA, 2017). Essa influência pode ser explicada devido às melhores condições edafoclimáticas sobre as comunidades fúngicas e bacterianas, que estão diretamente ligadas à qualidade sensorial do café (GOMES et al., 2020). Apesar de nenhuma das amostras ter apresentado a soma dos atributos ou nota global superior a 80 pontos, para serem classificadas como qualidade Specialty (SCAA, 2013), de acordo com os critérios da Conilon Brasil (2011), as notas obtidas classificam as amostras TC e $\mathrm{S}$ em "razoável" (notas entre 40 e 50 pontos) e TS em "boa" (notas entre 60 e 70 pontos), ambas demonstrando padrão comercial.

\section{CONCLUSÕES}

Houve diferença significativa entre os diferentes métodos de secagem utilizados para todos os parâmetros avaliados.

Com base nas análises realizadas, não foi possível identificar um único método de secagem que promovesse amostras com parâmetros superiores de qualidade, indicando, portanto, que o uso de matéria prima de boa qualidade, manejo e processamento pós-colheita adequados, a fim de se evitar processos fermentativos indesejados, proporcionam produtos finais dentro dos padrões de qualidade, independentemente do método de secagem utilizado.

\section{AGRADECIMENTOS}

Aos produtores de café, pelas amostras cedidas para realização da pesquisa. Ao Laboratório de Química do Instituto Federal do Espírito Santo, Campus Alegre, e Laboratório de Análise e Pesquisa em Café do Instituto Federal do 
Espírito Santo, Campus Venda Nova do Imigrante, pela realização das análises.

\section{REFERÊNCIAS}

ABRAHÃO, S. A.; PEREIRA, R. G. F. A.; DUARTE, S. M. S.; LIMA, A. R.; ALVARENGA, D. J.; FERREIRA, E. B. Compostos bioativos e atividade antioxidante do café (Coffea arabica L.). Ciência e Agrotecnologia, v. 34, n. 2, p. 414-420, 2010.

AFONSO JÚNIOR, P. C.; CORRÊA, P. C.; GONELI, A. L. D.; BOTELHO, F. M. Secagem, armazenamento e qualidade fisiologia de sementes do cafeeiro. Revista Brasileira de Armazenamento, v. Especial Café, n. 9, p. 67-82, 2006.

AFONSO JÚNIOR, P. C.; CORRÊA, P. C.; GONELI, A. L. D.; VILARINHO, M. C.; FRANÇA, A. S. Dinâmica da contração volumétrica do fruto de café durante o processo de secagem. Revista Brasileira de Armazenamento, v. Especial Café, n. 8, p. 29-35, 2004.

ASSOCIATION OF OFFICIAL ANALYTICAL CHEMISTS. Coffee and Tea. In: AOAC. (15. ed.) Official methods of analyses of the Association of Official Analytical Chemists. Washington, p. 3032, 1996.

BALZER, H. H. Acids in coffee. In: CLARKE, R. J.; VITZTHUM, O. G. (Ed.). Coffee: recent developments. London: Blackwell Science, p. 18-32, 2001.

BORÉM, F. M.; CORADI, P. C.; SAATH, R.; OLIVEIRA, J. A. Qualidade do café natural e despolpado após a secagem em terreiros e com altas temperaturas. Ciência e Agrotecnologia, v. 32, n. 5, p. 16091615, 2008.

BRASIL. Ministério Agricultura, Pecuária e Abastecimento. Regras para análise de sementes. Brasília, DF: SNDA, 1992.
BRASIL. Ministério da Agricultura, Pecuária e Abastecimento. Instrução Normativa $n^{0}$ 8, de 11 de junho de 2003. Aprova o regulamento técnico de identidade e de qualidade para a classificação do café beneficiado grão cru. Diário Oficial da União: seção 1. Brasília, DF, 13 de junho de 2003. Disponível em: https://www.gov.br/agricultura/pt-

br/assuntos/inspecao/produtosvegetal/legislacao-1/normativoscgqv/pocs/instrucao-normativa-no-8-de11-de-junho-de-2003-cafe-grao-cru/view. Acesso em: 19 de outubro de 2020.

CARVALHO, V. D. de; CHAGAS, S. J. R.; CHALFOUN, S. M.; BORTREL, N.; JUSTE JÚNIOR, E. S. G. Relação entre a composição físico-química dos grãos de café beneficiado e a qualidade da bebida do café. Pesquisa Agropecuária Brasileira, v. 29, n. 3, p. 449-445, 1994.

CONAB. Acompanhamento da safra brasileira de café, v. 5 - Safra 2019, n. 4 Quarto Levantamento, Brasília, p. 1-44, dez. 2019.

CONILON BRASIL. Novo protocolo de degustação de robustas é testado: Cafés capixabas obtiveram resultados animadores. Revista Conilon Brasil, v. 2, n. 8, p. 10-11, 2011.

FERRÃO, M. A. G. et al. Origem, dispersão, taxonomia e diversidade genética de Coffea canephora. In: FERRÃO, R. G. et al. Café Conilon. (2 ed.) Vitória: Incaper, p. 81-97, 2017.

FRANCA, A. S.; OLIVEIRA, L. S.; MENDONÇA, J. C. F.; SILVA, X. A. Physical and chemical attributes of defective crude and roasted coffee beans. Food Chemistry, v. 90, p. 89-94, 2005.

GARCIA, D. C.; BARROS, A. C. S. A. A secagem de sementes. Ciência Rural, v. 34, n. 2, p. 603-608, 2004. 
GOMES, T. et al. Effects of environmental factors on microbiota of fruits and soil of Coffea arabica in Brazil. Scientific Reports, p. 1-11, 2020.

IAL. Instituto Adolfo Lutz. Métodos físico-químicos para análise de alimentos. 4. ed. São Paulo: Instituto Adolfo Lutz (Versão eletrônica), 2008.

ICO. INTERNATIONAL COFFEE ORGANIZATION. Dados Históricos. 2019. Disponível em: http://www.ico.org/pt/new_historical_p.asp ?section=Estat\%EDstica. Acesso em: 06 mar. 2020.

INCAPER. Instituto Capixaba de Pesquisa, Assistência Técnica e Extensão Rural. Cafeicultura. 2018. Disponível em: https://incaper.es.gov.br/cafeicultura. Acesso em: 05 mar. 2020.

LACERDA FILHO, A. F.; SILVA, J. S.; SEDIYAMA, G. C. Comparação entre materiais de pavimentação de terreiro para a secagem de café. Revista Brasileira de Armazenamento, v. Especial Café, n. 9, p. 83-93, 2006.

LAMBOT, C. et al. Evaluation of Conilons for genetic diversity, cup quality and biochemical composition. In: ASIC. Association for Science and Information on Coffee (Ed.) Proceedings of the 22nd International Conference on Coffee Science: Campinas, SP, 2008.

MORELI, A. P. et al. Quality of the arabic coffee in different altitudes in the Espírito Santo state. 2019, Vitória: [s.n.], 2019.

PEREIRA, L.L.; MORELI, A.P.; MOREIRA, T.R.; SCHWENGBER, C.; CATEN, T.; PAULO, J.; MARCATE, P. Improvement of the Quality of Brazilian Conilon through Wet Processing: A Sensorial Perspective. Agricultural Sciences, v. 10, n. 3, p. 395-411, 2019.
PEREIRA, L. F. B.; BARBOSA, C. K. R.; JUNIOR, K. S. F. The influence of natural fermentation on coffee drink quality. Coffee Science, Lavras, v. 15, n. 6, p. e151673, 2020.

PEREIRA, L. L. Novas abordagens para produção de cafés especiais a partir do processamento via-úmida. 2017. 200 f. Universidade Federal do Rio Grande do Sul, 2017.

PIMENTA, C. J.; PEREIRA, M. C.; CHALFOUM, S. M.; ANGELÍCO, C. L.; MARTINS, R. T. Avaliação físico-química e de qualidade do café (Coffea arabica L.) submetido a diferentes tempos de espera para secagem. Revista Brasileira de Armazenamento, v. Especial Café, n. 10, p. 29-35, 2008.

PIMENTA, C.J. Qualidade de café. Lavras: Editora UFLA, p.147-158, 2003.

PRETE, C. E. C. Condutividade elétrica do exsudato de grãos de café (Coffea arabica L.) e sua relação com a qualidade da bebida. 1992. 125 f. Tese (Doutorado) - Escola Superior de Agricultura Luiz de Queiroz, 1992.

RODRIGUES, W. P. et al. Long-term elevated air [CO2] strengthens photosynthetic functioning and mitigates the impact of supra-optimal temperatures in tropical Coffea arabica and $C$. canephora species. Global Change Biology, v. 22, n.1, p. 415-431, 2015.

SANTOS, M. A.; CHALFOUN, S. M.; PIMENTA, C. J. Influência do processamento por via úmida e tipos de secagem sobre a composição físico química e química do café (Coffea arabica L.). Ciência e Agrotecnologia, v. 33, n. 1, p. 213-218, 2009.

SANTOS, T. F. dos. Monitoramento da qualidade do café por meio de análise molecular usando pcr em tempo real. 
2019. 141 f. Universidade Federal do Rio de Janeiro - UFRJ, 2019.

SCAA. Specialty Coffee Association of American. Protocols.2013. Disponível em: https://www.scaa.org/PDF/resources/cuppi ng-protocols.pdf. Acesso em: 05 mar. 2020.

SEMEDO, J. N. et al. Coffee responses to drought, warming and high [CO2] in a context of future climate change scenarios. Climate Change Management, p. 465477, 2018.

SILVA, J. S.; LACERDA FILHO, A. F. Construção de um secador para produtos agrícolas. Imprensa Universitária, 1984. (Informe Técnico 41)

SIQUEIRA, H.H.; ABREU, C.M.P. Composição físico-química e qualidade do café submetido a dois tipos de torração e com diferentes formas de processamento. Revista Ciência e Agrotecnologia, v.30, n.1, p.112-117, 2006. 